\title{
Mannerisms of Millennials - How they Perceive vs How they are Perceived
}

Laura Christ Dass, Geetha Subramaniam, Noor Hanim Rahmat

To Link this Article: http://dx.doi.org/10.6007/IJARBSS/v11-i2/8390

DOI:10.6007/IJARBSS/v11-i2/8390

Received: 03 January 2021, Revised: 26 January 2021, Accepted: 10 February 2021

Published Online: 25 February 2021

In-Text Citation: (Dass et al., 2021)

To Cite this Article: Dass, L. C., Subramaniam, G., \& Rahmat, N. H. (2021). Mannerisms of Millennials - How they Perceive vs How they are Perceived. International Journal of Academic Research in Busniess and Social Sciences. 11(1), 632-646.

Copyright: (c) 2021 The Author(s)

Published by Human Resource Management Academic Research Society (www.hrmars.com)

This article is published under the Creative Commons Attribution (CC BY 4.0) license. Anyone may reproduce, distribute, translate and create derivative works of this article (for both commercial and non-commercial purposes), subject to full attribution to the original publication and authors. The full terms of this license may be seen

at: http://creativecommons.org/licences/by/4.0/legalcode

Vol. 11, No. 2, 2021, Pg. 632 - 646

Full Terms \& Conditions of access and use can be found at http://hrmars.com/index.php/pages/detail/publication-ethics 


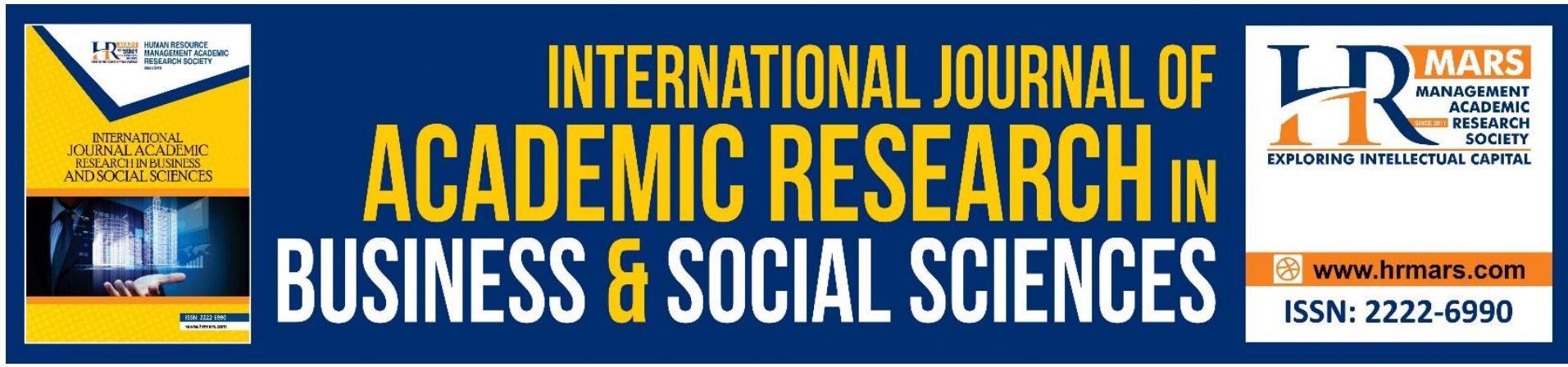

\title{
Mannerisms of Millennials - How they Perceive vs How they are Perceived
}

\author{
Laura Christ Dass (Main Author) \\ Academy of Language Studies, Universiti Teknologi MARA 40450 Shah Alam, Selangor, \\ Malaysia. \\ Email: lauradass23@yahoo.com
}

\begin{abstract}
Geetha Subramaniam (Corresponding Author)
Faculty of Business and Management, Universiti Teknologi MARA 40450 Shah Alam, Selangor, Malaysia.

Email: geethamaniam@gmail.com
\end{abstract}

\author{
Noor Hanim Rahmat (Co-Author) \\ Academy of Language Studies, Universiti Teknologi MARA 40450 Shah Alam, Selangor, \\ Malaysia. \\ Email: noorh763@uitm.edu.my
}

\begin{abstract}
It is widely known that the Generation $\mathrm{Y}$ or more popularly known as the millennials have a set of distinct universal characteristics that set them apart from the older generation. These characteristics among others include their lack of good mannerisms in their daily interaction regardless of whether it is with their own contemporaries or with those older. This research aims to get some perspectives on the mannerisms and attitudes of the Generation $Y$ from their own perspective and that of the older generation that is largely responsible in nurturing them. A total of more than 100 respondents from each category participated in this study. It is interesting to discern a certain degree of difference in the set of values held by our young of today in comparison to the generation before them. This study found a consistent pattern in which the millennials viewed themselves more positively in comparison to the perception of the older generation of their attitudes and mannerisms.
\end{abstract}

Keywords: Millennials, Attitudes and Mannerisms, Generation X, Generation Y, Values, Politeness.

\section{Introduction}

The younger generation today in particular the Generation $Y$ (born between 1980 and 2000) is different from the generations before them in many aspects including characteristics, outlook in life, dress pattern, film and literature, family pattern, knowledge of the English language, education level, food habit, religious behaviour, social behaviour, technology and so on. One aspect however stands out as most prominent over others, at least from the 
perspective of the older generation. It is the characteristics of these young people that has become an area of contention among Generation X or earlier regardless of race, culture, creed or religion. It is a universal trait today among the millennials that they lack values and respect not only for parents, grandparents, teachers and elders but also for each other. Arumugam, Dass, Alias, Kaur, Abdul Murad, and Nayan (2015, p.48) highlighted this feature of the millennials in their book '...they are known to lack virtues highly regarded by societies of the earlier generations'.

This is a worrying trend that needs to be tackled for without good values such as politeness and courtesy, society is at risk of sliding backwards in civilisation. Politeness among human beings has always been a symbol of human civilization in all cultures, it has a crucial role in establishing and keeping good relationships and maintaining social harmony (Sezan, 2012). To ignore that there is a real problem with the mannerisms of our young people is turn a blind eye to the 'elephant in the room' also called willful blindness by Heffernan (2011). This author also stresses the dangers of willful blindness and the importance of acknowledging and addressing issues around us both big and small.

In order to have a clearer understanding of this phenomenon, a study was carried out to gauge the general perspective of society on the characteristics of the millennials. The purpose of this study therefore, is to gather information from two categories of people who could shed light on their behaviours. The first category of people include parents, teachers and guardians, the very people responsible for raising and nurturing the Gen Y. The second category of people is none other than the millennials themselves to find out what they perceive of the characteristics of the young people like themselves.

The findings show that the Malaysian millennials feel it is fine to be different and to go ahead with what they think is right. As Twenge (2006) found that this kind of mannerism which does not conform to the societal norms and social rules does not seem to be wrong to them. It also conforms to studies by Tamban and Lazaro (2018) where millennials' generally had positive perception of themselves. A major contributor to the difference in characteristics of millennials is perhaps their exposure to world digitalization as they matured which may have instilled in them the confidence and power to make decisions for themselves (Roslan \& Subramaniam, 2020). Could this also be a reason for the expectation of higher than reasonable salary by over $32 \%$ of Malaysian fresh graduates (Kadir, Naghavi, Subramaniam, \& Halim, 2020)?

\section{The Objectives of this Research}

1. To study the Gen Y's perception of their attitudes and mannerisms in their daily lives.

2. To study the older generation's perception of the attitudes and mannerisms of Gen $Y$ in their daily lives.

The Research Questions of this study:

1. What is the Gen Y's perception of their attitudes and mannerisms in their daily lives?

2. What is the older generation's perception of the attitudes and mannerisms of Gen $Y$ in their daily lives?

\section{Literature Review \\ Defining the Millennials}

The term millennials generally refers to the generation of people born between the early 1980 s and the early 2000s. The Millennial Generation is also known as Generation Y, 
because it comes after Generation X. Gen X refers to those people born between the early $1960 \mathrm{~s}$ and the 1980s. By virtue of the universality of their character and attitude, the millennials are presenting themselves to the world as a legion that cannot be ignored.

Millennials, the first generation to come of age in the new millennium are those born between the early 1980 s and early 2000 . This means that in 2020, they are in their 20 's to early 40 years of age and have mostly joined the workforce. This is a generation that was born in fastphase era, surrounded by the modern technology such as digital media, the internet, mobile phones, instant communication and social networking. Many studies point to this reality, according to Pandian, Baboo, and Yi (2020, p.351) 'More crucially, the global and local world brings dramatic politics, current events, entertainment and celebrity news, scientific research ... impinge upon students' beliefs, ideas, values and decision-making capacities...'

This generation grew up at a time when the world was being transformed by new technologies that changed the way people communicated, worked, and information exchanged information (Mulyana, Soeaidy, \& Taufiq, 2019). All of these are said to have profound effects on their civic mindedness and sense of morality (Manning, 2013).

\section{The Role of Politeness in Establishing Good Relationships}

Politeness is a symbol of human civilization that can be found in all languages and cultures. It has always been considered as one of the basic social doctrines for human interactions, which plays a crucial role in establishing and keeping good relationships and maintaining social harmony. Yan (2015) establishes that cross-cultural communications could be more successful and effective by understanding these cultural differences.

The author further reiterates that politeness is the behavior standard to show mutual respect and friendliness among human contacts and exchanges, besides, it is also the most basic requirement of civilized behavior. Politeness is all about respecting others, which has time and again been proven a stepping-stone to achieve successful relationships.

\section{Attitudes and Mannerisms of the Millennials}

The many studies conducted have led to the millennials being characterised in a number of different ways. They are generally regarded as being more open-minded, confident, selfexpressive, liberal, upbeat and receptive to new ideas and ways of living. These individuals of the digital generation are able to make informed choices as consumers of services and products as they possess information right at their finger tips. This generation grew up at a time when the world was being transformed by new technologies that changed the way people communicated, worked, and information exchanged information (Mulyana, Soeaidy, \& Taufiq, 2019).

Above all else, Gen Y seeks work-life balance, a characteristic that is a far cry from the hard working generation their parents belong to (Hee \& Rhung, 2019). Though the Gen Y proves to be an outspoken lot who speak their minds, their desires for authenticity in work and life relationships and yearn for leaders who walk their talk doesn't make them dissimilar from the previous generations. 
On the negative side, the Gen $\mathrm{Y}$ has been described as lazy, narcissistic, prone to jump from job to job and have unrealistic expectations of working life. The trend is more of an emphasis on extrinsic values such as money, fame and image, and less emphasis on intrinsic values such as self-acceptance, group affiliation and community (Arumugam et al., 2015). In other words, they are known to lack virtues highly regarded by societies of the earlier generations. Thus, leaving the onus of setting the Gen $Y$ right all over again, on the shoulders of the older generation who otherwise would risk losing all cultural values held dear, for good!

Good manners are part of having a good personality and the right personality is vital for successful learning in school. According to Awang, Dollah, Yusof, Hanafi, and Faiz (2017) how effectively a learner acquires knowledge and skills taught is determined by both the learner's individual personality and learning styles. There are many studies that show a link between attitude and behaviour (Li, Luqman \& Ishak, 2019), which brings to question the very attitude or core belief of our millennials. This is cause for concern as the wisdom and life experiences of the older generation are valuable which the younger generations can benefit from (Meng, 2019). If the young fail to humble themselves to respect and learn from the older generation, it is all but a loss for them.

The worrying trend among our young people is cited by Chung (2019), "A recent poll found that $62 \%$ of Malaysians worry about growing old with more than half feeling there is a lack of respect for the elderly." Sezan (2012) conducted a study on the impact of western cultures on the Bangladeshi society noted that social customs, values and norms are important means of any country's culture. He added that Bangladesh is not exceptional, in our culture, there are various practices of social customs such as, respecting elders, be affectionate to youngers etc. Upon these social customs, there is also impact of western culture, these types of social customs are not practiced much especially by the younger generation who are the most vulnerable and exposed to modern cultures from the west.

Gomes and Rahman (2010) noted in a report of the various implications both positive and negative the western culture may have on other societies. Lamare (2009) in explaining cultural globalization, also mentioned how globalization of culture has profound effects on Asian and African countries, in particular that of USA. So strong is its influence perceived to be by some nations that, the European Union has developed policies to impose 'a trade barrier to limit American entertainment imports in the name of cultural preservation' to minimise the influence of American culture on their society or more specifically their young generation. (Khan \& Arif, 2009).

\section{Methodology}

\section{Research Instruments and Respondents}

This research utilised both qualitative and quantitative research methodology, the instruments used include questionnaire using online google survey forms and interview. Respondents for the survey were randomly selected from two sets of age groups. Two sets of questionnaire and interview questions were prepared for the different category of respondents. Group A (respondents comprise of Gen Ys). Group B (respondents comprise of parents, teachers or guardians of Gen $Y$ who belong to Gen X or the generation before). The questionnaires for both groups of participants included different question types such as yesno, ranking, category, scales and open-ended questions. Interview questions were generally 
open-ended aimed to validate data obtained through questionnaires as well as to probe further questionnaire responses.

\section{Data Collection and Analysis Method}

Questionnaire links were sent out to the mobile gadgets of selected participants both via Whatsapp chat groups and individually. Responses started trickling in almost immediately and after 2 weeks, a total of 126 and 101 responses were collected respectively from the different groups of respondents. Quantitative data were analysed by Google forms through frequency counts and other descriptive statistics. Results were presented in the form of pie-charts and bar-graphs. Qualitative data was transcribed and analysed using the coding technique to identify patterns and themes that emerged from the analysis.

\section{Findings and Discussion}

This section on data analysis and discussion of findings is categorised into several sections including analysis of demographic information respondents, followed by analysis of questions pertaining to the attitudes and mannerisms from the perspectives of Group A respondents (millennials) followed by those of Groups B respondents (parents, teachers \& guardians). It would be interesting to observe how the millennials perceive of themselves first followed by the perspective of the older generation. This could enable a comparison and confirmation to be made of the perspectives of the millennials by the older generation.

\section{Demographic Information}

\begin{tabular}{|r|r|r|r|}
\hline Respondents & Male (\%) & Female (\%) & Total(\%) \\
\hline Group A & 18 & 82 & 100 \\
\hline Group B & 14.9 & 85.1 & 100 \\
\hline
\end{tabular}

There were 126 Group A(millennials) respondents, comprising of $82 \%$ female and $18 \%$ male respectively. Group B respondents numbered 101 , comprising of $85.1 \%$ and $14.9 \%$ male.

\subsection{1}

A. When you are talking to someone older.

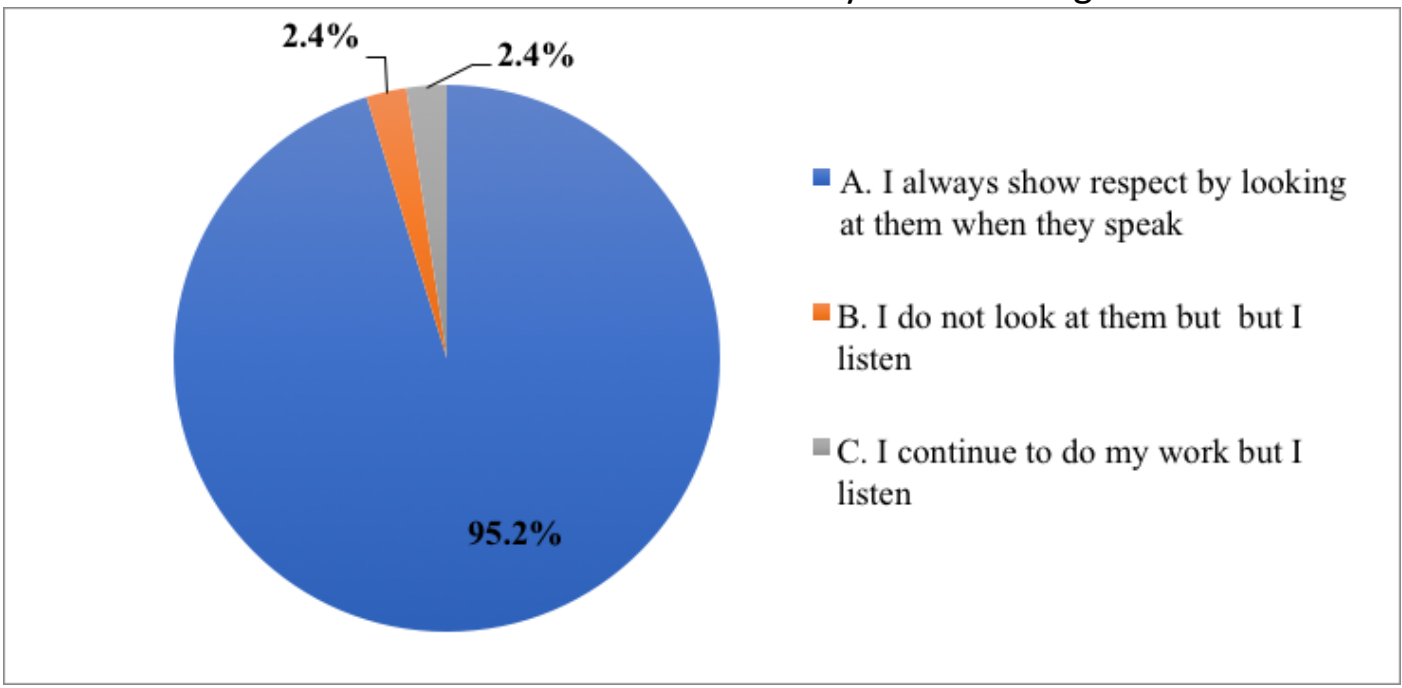

Figure 4.2.1A

A. When a Gen $Y$ or $Z$ is talking to someone older 


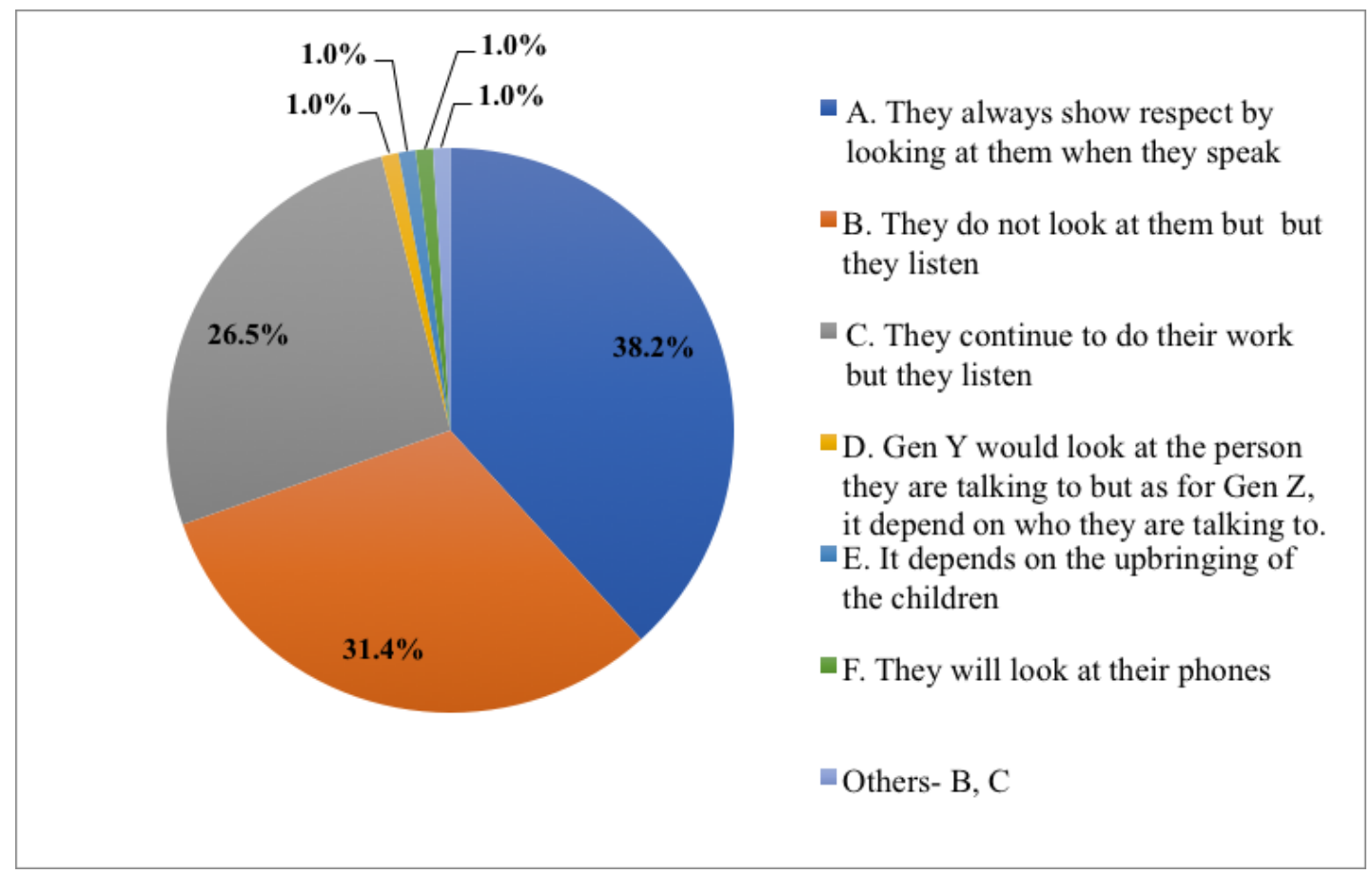

Figure 4.2.1.B

The response of the millennials show that $95.2 \%$ chose Option A - that is they always show respect to someone older by looking at them when they speak. Only a minority of $4.8 \%$ chose either Option B or C- that is they do not look but listen or continue their work but listen.

In comparison to the findings above, only $38.2 \%$ of Group B respondents agreed with the respondents of Group A in respect to Option A. The majority of respondents or $57.9 \%$ chose either Option B or C. A minority of $4 \%$ chose other options ranging from D $-F$.

\subsection{2}

A. When you are are at the door with someone older.

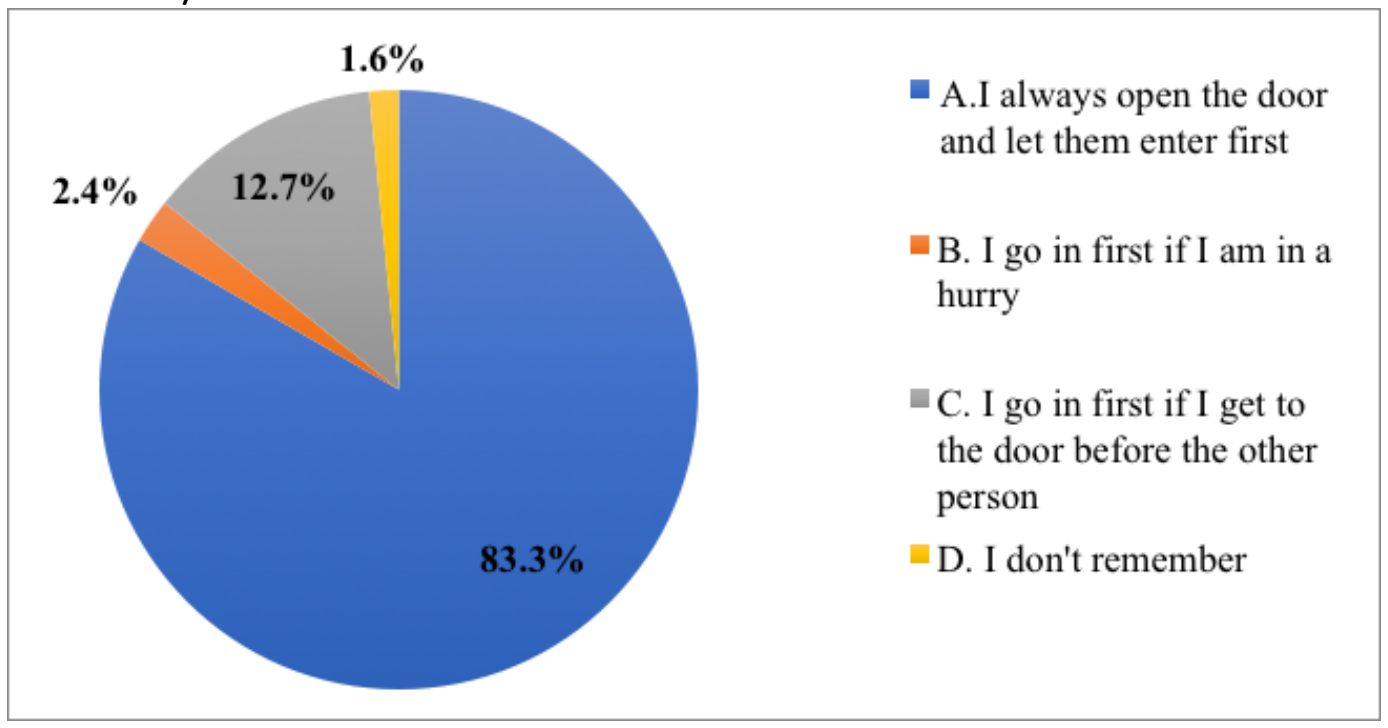

Figure 4.2.2.A

B.When a Gen $\mathrm{Y}$ or $\mathrm{Z}$ is at the door with an older person 


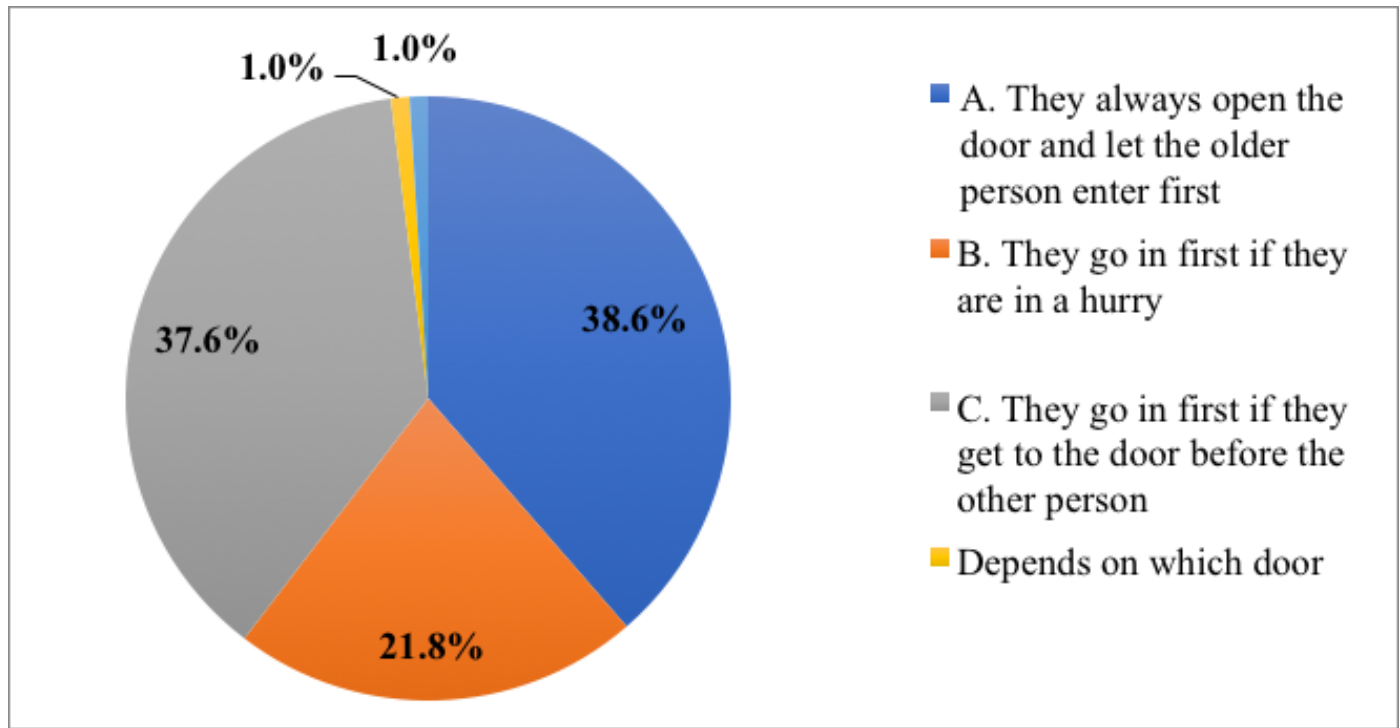

Figure 4.2.2.B

An overwhelming 83.3\% of Group A respondents chose Option A - I always open the door and let them enter first believe that while a smaller percentage of $12.7 \%$ admitted to going in first if they get to the door before the older person (Option C).

Responses from the Group B participants however chose to defer to a certain degree from Group A, with $38.6 \%$ and $37.6 \%$ selecting Options $A$ and $C$ respectively. A substantial number of respondents or $21.8 \%$ chose Option $\mathrm{B}$ - they go in first if they are in a hurry.

\subsection{3}

A. When talking to an older family member e.g parents, grand parents, uncle, aunt etc.

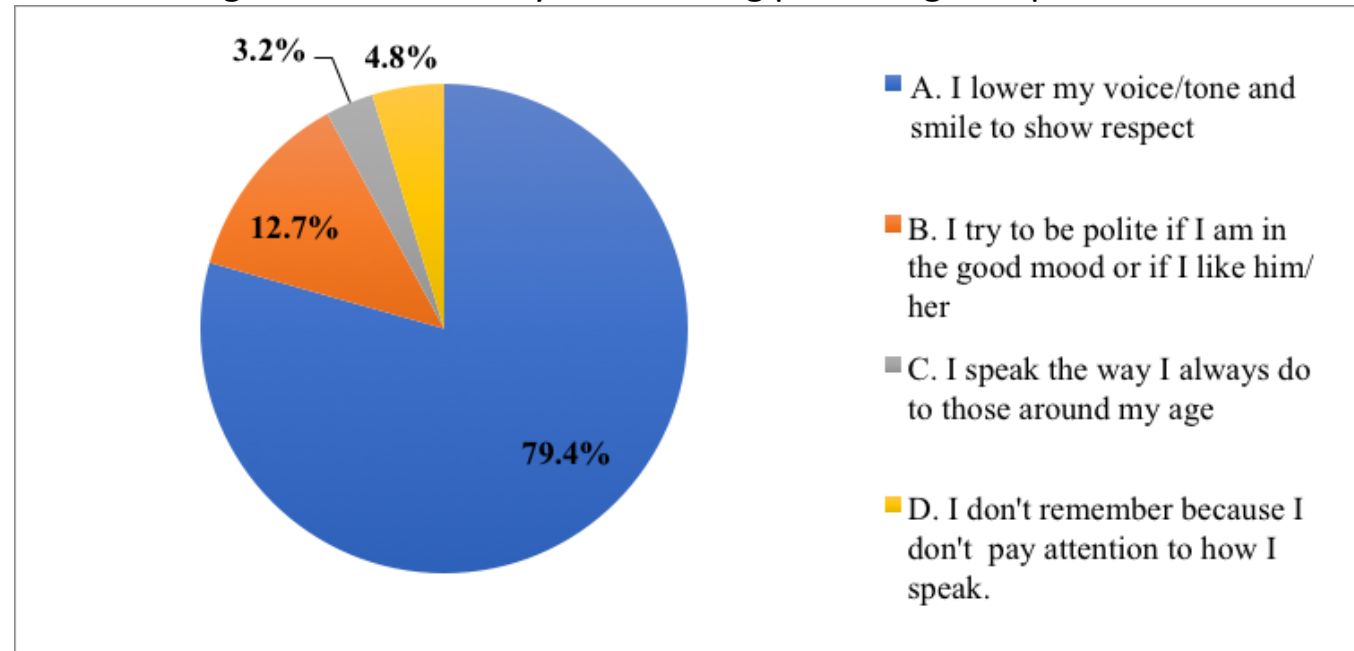

Figure 4.2.3A

B. When talking to an older family member e.g parents, grand parents, uncle, aunt etc. 


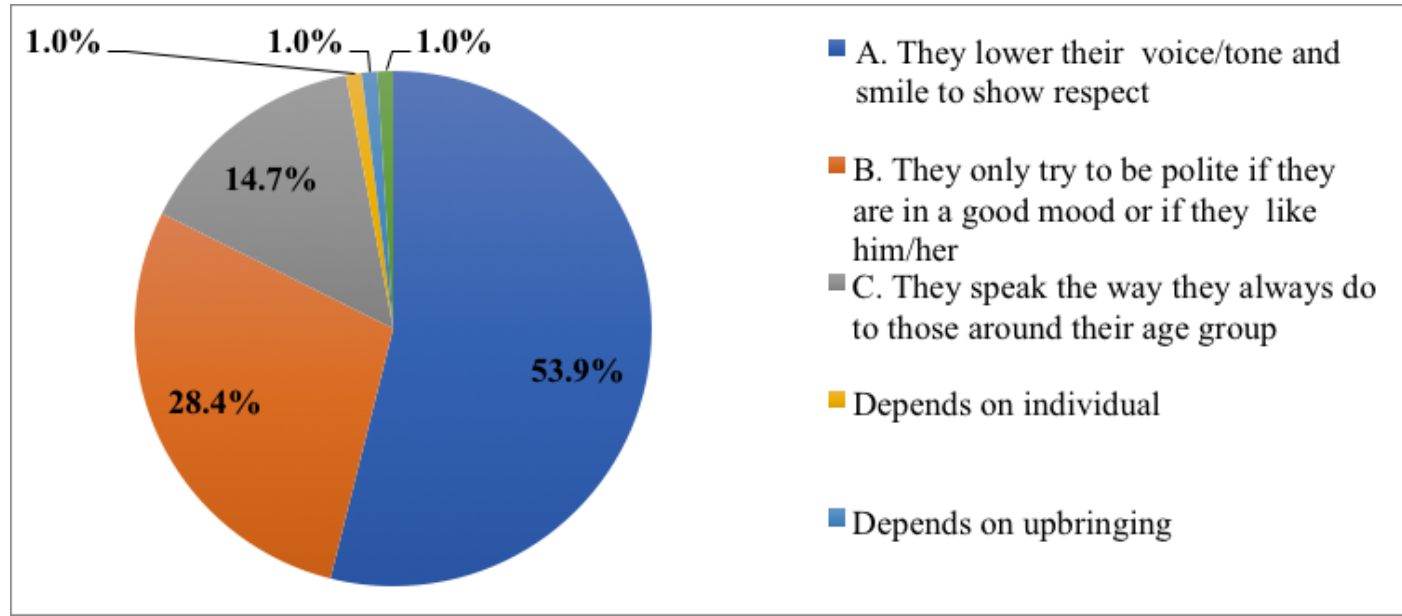

Figure 4.2.3.B

Another instance of millennials rating themselves high is seen where $79.4 \%$ of the respondents in this category chose Option A - I lower my voice/tone and smile to show respect and a smaller percentage of $12.7 \%$ indicated that they try to be polite if they are in a good mood or they like the person by their choice of Option B.

Group $B$ responded to this question with a big portion of $53.9 \%$ in agreement with the millennials. A substantial number of $28.4 \%$ chose Option B - They try to be polite if they are in a good mood or if they like the teacher while a smaller percentage of $14.7 \%$ indicated by their choice of Option $C$ that millennials speak in a similar manner regardless of age group.

\subsection{4}

A. When you are in a discussion with an older person.

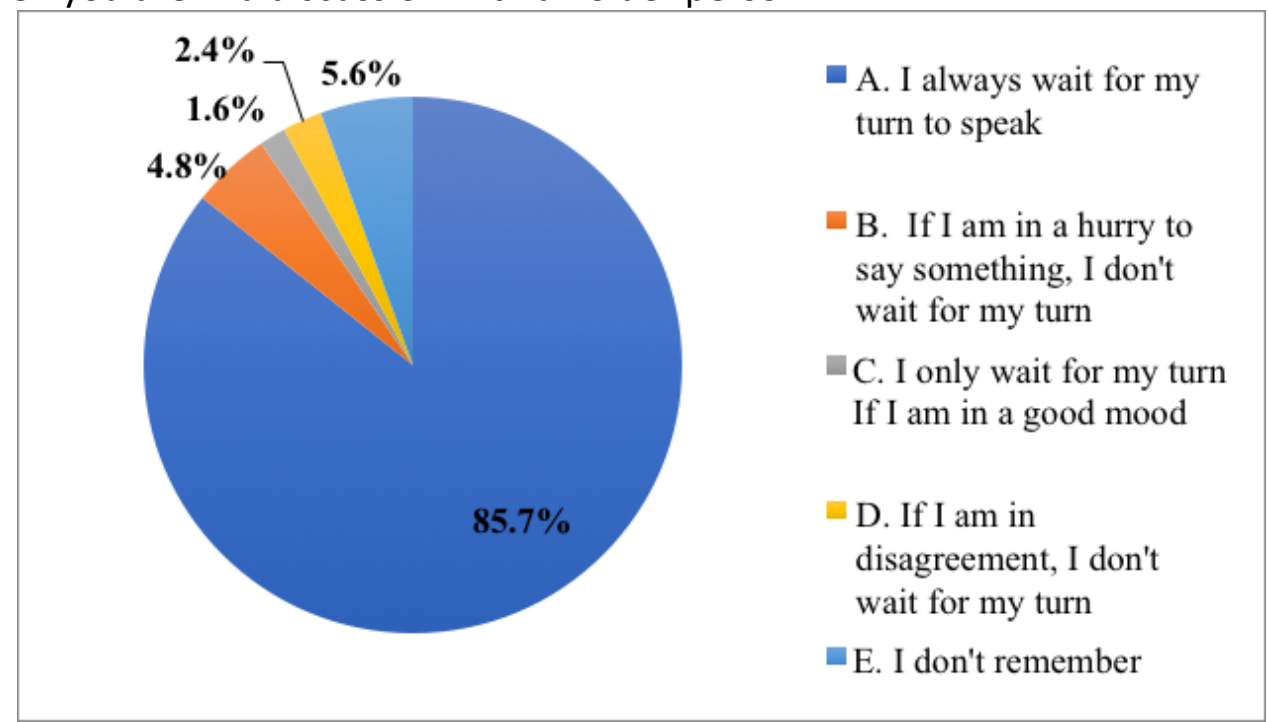

Figure 4.2.4A

B. When in a discussion with an older persons 


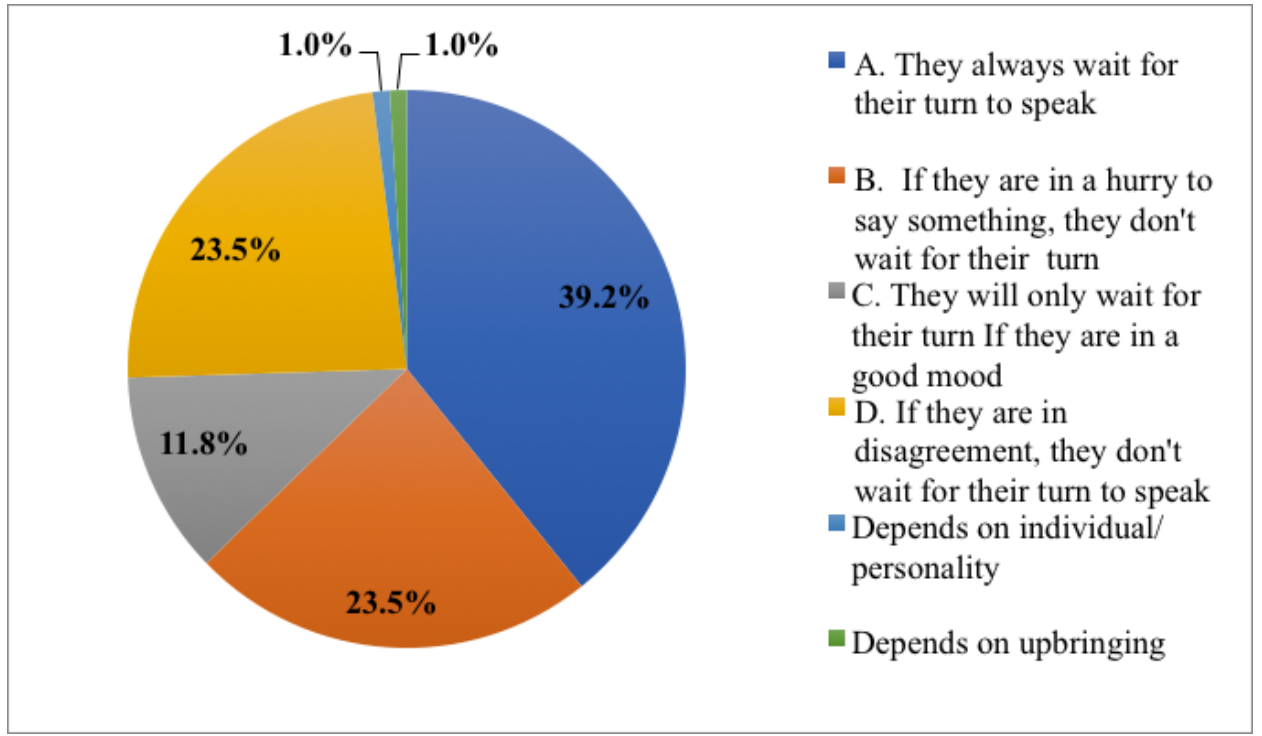

Figure 4.2.4.B

The pie chart above falls into the regular pattern of previous responses with a big majority of $85.7 \%$ of optimistic millennial respondents choosing Option A - I always wait for my turn to speak while only a small percentage of $4.8 \%$ of them admitted to Option B - If I am in a hurry to say something I don't wait for my turn. $5.6 \%$ selected Option $E$ as they could not remember how they would react in such a situation.

The older generation as with previous situations do not appear as optimistic, with only $39.2 \%$ of the respondents agreeing with the millennials on Option A. $23.5 \%$ chose Options B - If they are in a hurry to say something, they don't wait for their turn and D - If they are in disagreement, they don't wait for their turn to speak. A smaller percentage of $11.8 \%$ chose Option C- They will only wait for their turn if they are in a good mood.

\subsection{5}

A. How would you rate the importance of politeness in your daily life? (On a scale of 1: least important - 5: most important)

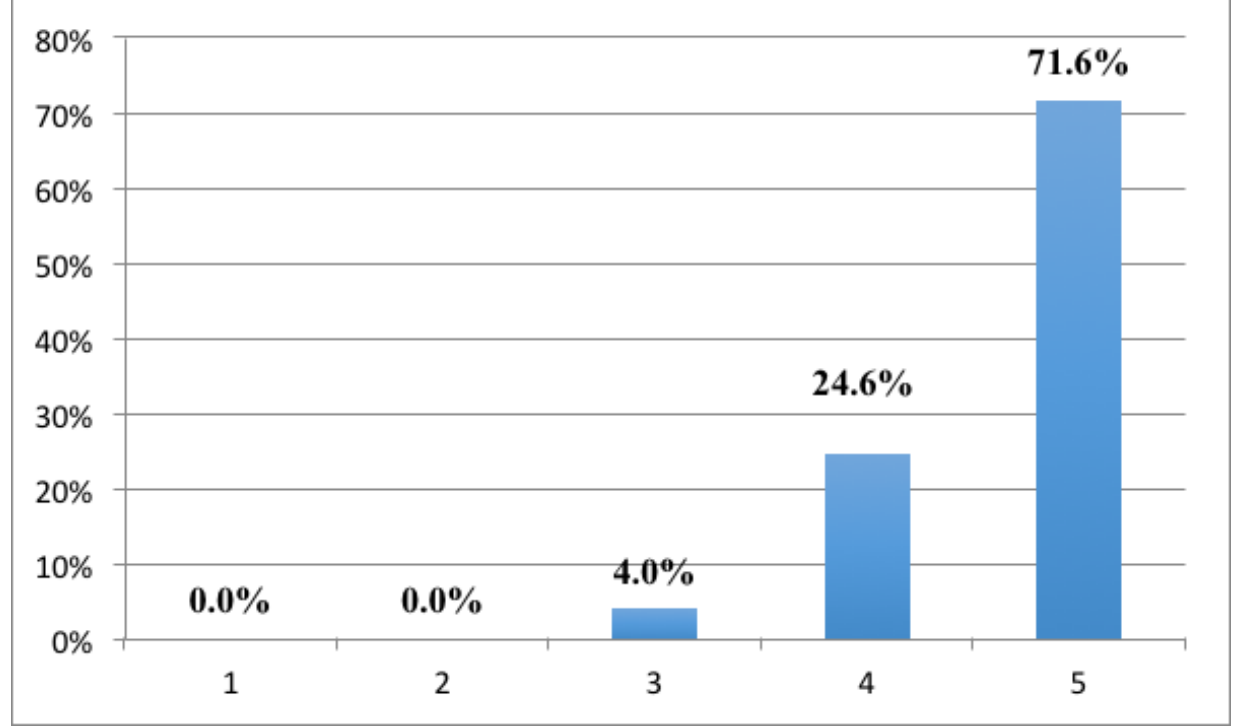

Figure 4.2.5A 
B. How would you rate the importance of politeness among Gen $Y$ \& $Z$ in their daily lives? (On a scale of 1 : least important - 5 : most important)

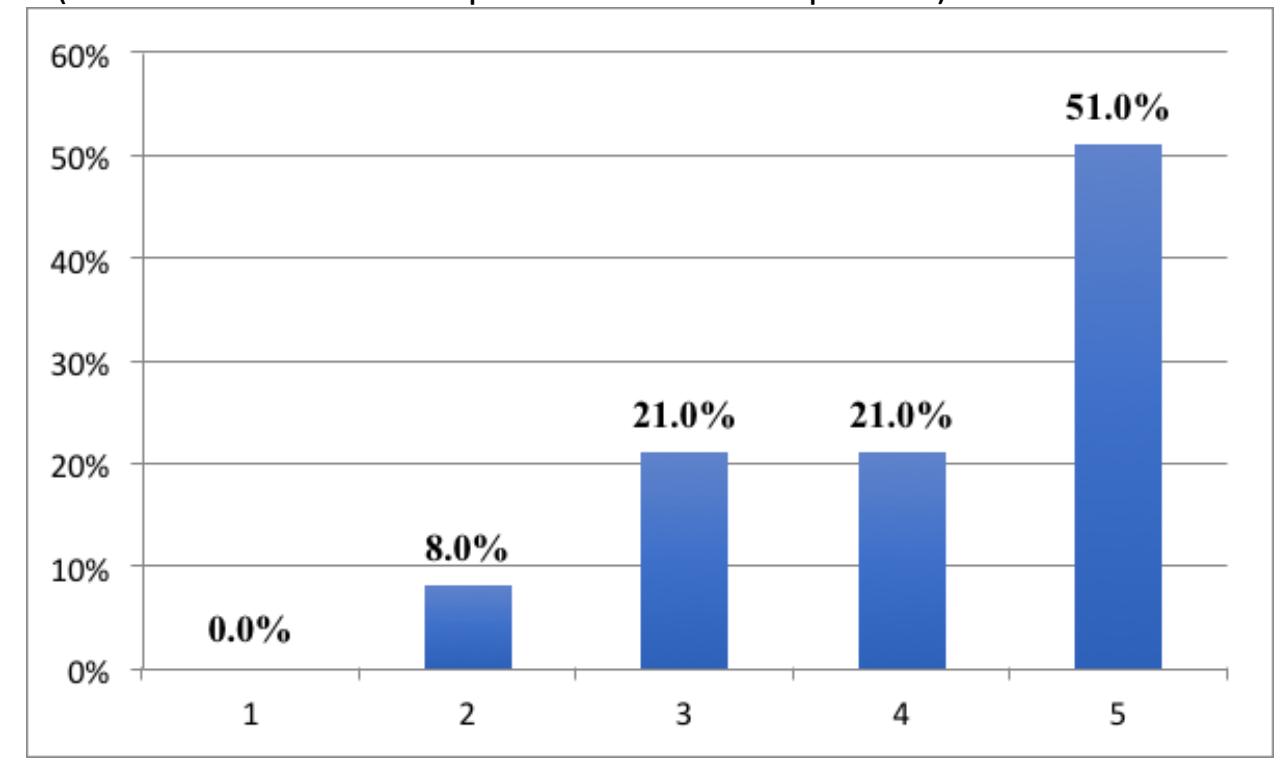

Figure 4.2.5B

In response to a question on how important politeness is perceived, a majority of $96 \%$ of millennials respondents rated it as at least very important with a huge percentage of $71.4 \%$ rating politeness as most important.

Although a majority of the millennials rated very high the importance of politeness, Group B respondents did not agree as much. $71 \%$ thought that millennials perceive as important, $21 \%$ were of the opinion that millennials perceived it as average in importance while $8 \%$ even thought that politeness was unimportant to the younger generation.

\section{6}

A. How would you rate yourself on a politeness scale? (1: least polite- 5: very polite)

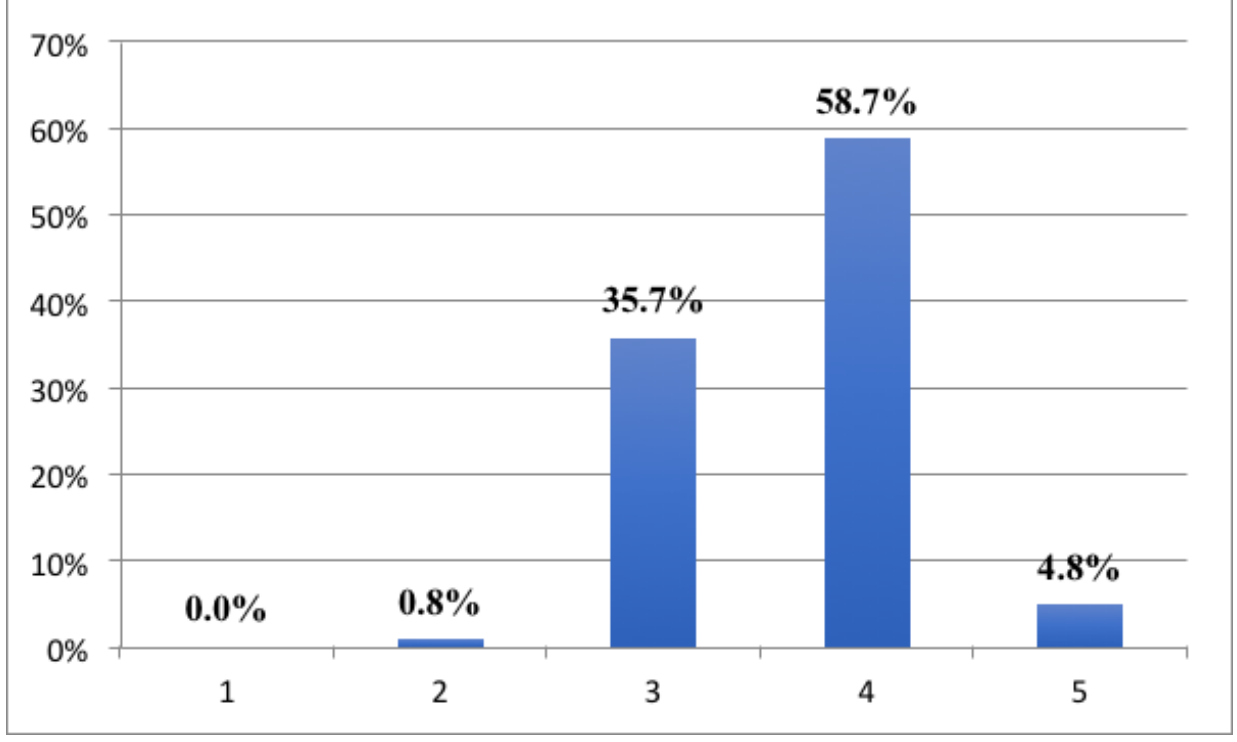

Figure 4.2.6.A 
B.How would you rate Gen $Y$ and $Z$ on a politeness scale? ? (1: least polite- 5: very polite)

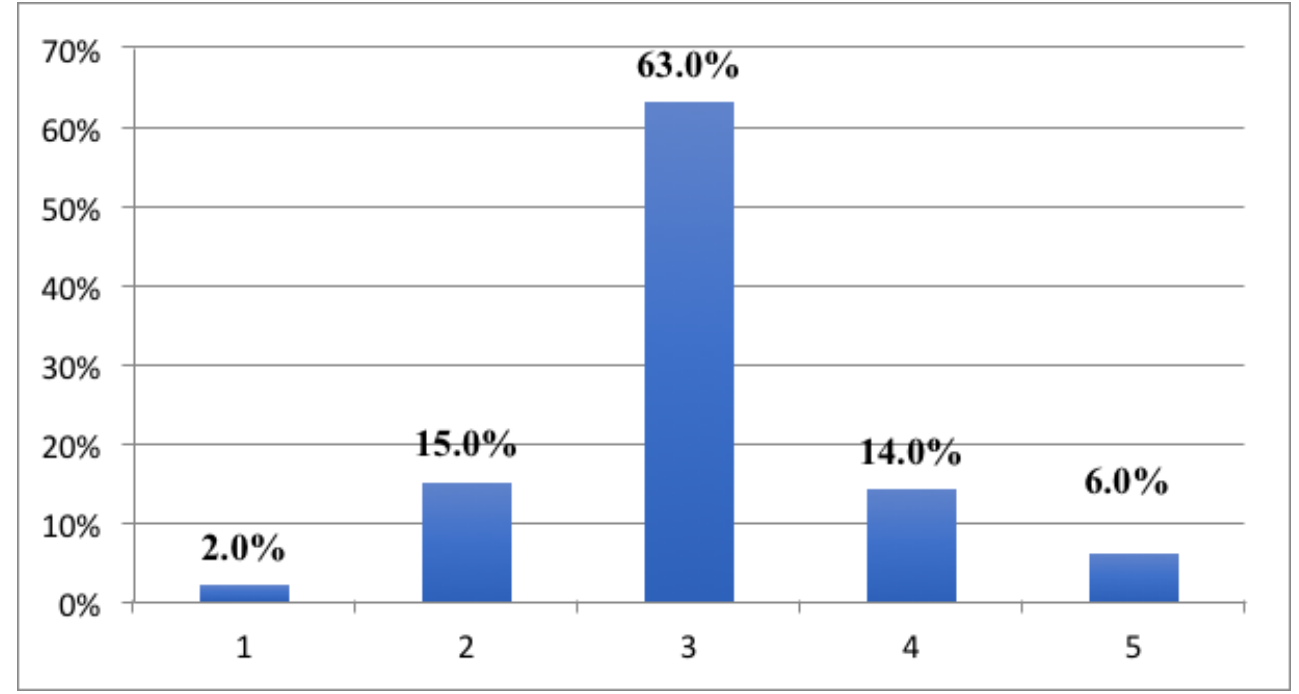

Figure 4.2.6.B

Millennial participants once again displayed their confidence in their attitude and mannerisms with a majority of $63.5 \%$ rating themselves as either polite or very polite. $35.7 \%$ rated themselves as average on the politeness scale while $0.8 \%$ admitted to being less polite. No participant rated themselves as least polite.

On the other hand, Group B respondents were not as impressed with the millennial's projection of politeness. A smaller percentage of $20 \%$ found the younger generation to be polite, while a majority of $63 \%$ rated them as merely average. $17 \%$ categorised them as not polite with a $2 \%$ of respondents who even considered the millennials to be least polite.

\section{Discussion of Findings}

The survey generally provided a number of options to participants ranging from $3-9$, depending on the situation given. Options A across the board generally indicate the best behaviours an individual or in this study millennials could display. This was followed by Options B - Options I that indicate behaviours that are less favourable displayed by our millennials.

This study found a stark difference in the way millennials (Group A) rated themselves compared to the way the older generation (Group B) rated them. In every scenario given, the millennials rated themselves higher than did the older group. Option A was selected by far more millennials in every situation posed, as an indication of their own mannerism than their parents or teachers. The difference in percentage ranged between $12.1 \%-57 \%$ for the two groups under study, with the difference exceeding more than $30 \%-50 \%$ in most instances. On the other hand, the responses for Options $C$ which were indicative of behaviours less favoured, were reversed. Each of the given situation had a higher percentage of Group B responses for this option, the differences ranged between $9.8 \%-28.7 \%$. This is a clear suggestion of the older generation's perception of the behaviours and mannerisms of the millennials to be less favourably than they themselves (millennials) believed.

This is an important finding that highlights the discrepancy in the perception of the millennials about their own behaviour versus that of the generation that is responsible for raising and nurturing them. This study indicates that the very group of people who nurtured and built character in the millennials appear to be less impressed with the mannerisms of their young compared to the millennials themselves. 
Results obtained for the next two questions add validity to the findings above. The millennials believed that politeness is an important virtue to have where an overwhelming $96 \%$ rated politeness as either important or very important to them. In comparison, only $71 \%$ of the older generation approved of this while a further $21 \%$ rate this virtue as only average in importance with a smaller percentage of $8 \%$ even convinced that politeness was unimportant to the millennials. None of the millennials indicated politeness as unimportant in this survey. The next question that tests how the two groups of participants rated millennials on a scale of $1-5$ on politeness found $58.7 \%$ of millennials rating themselves as polite with only $14 \%$ the older generation agreeing with them. Majority of the older generation or $63 \%$ sited the millennials as just average on this scale with a $17 \%$ even being unimpressed with the mannerisms of their young by rating them as either lowest or second lowest on the scale of politeness. None of the millennials rated themselves the lowest for this question.

This is indicative of a worrying trend in our modern world, given that the millennials are aware of importance of politeness and know what constitutes polite behaviour as they cited in this study. When asked how they would define politeness, they cited a list of behaviours and vocabulary such as respect, kindness, greet one another, lower voice especially when talking to those older, holding out the door for them, well mannered, remember to thank people or say 'excuse me' when needed etc. These are precisely the types of attitude and behaviour favoured by the older generation. It also brings to light an important fact that the millennials are able to spell out good behaviour hence reflecting the good work done by their parents, guardians and teachers in inculcating these desirable behaviour in them.

The question that remains despite the finding that the millennials are indeed well able to distinguish good from poor mannerism and behaviour is why do they fall short of the expectations of the older generation. It seems clear here that knowledge of good behaviour need not necessarily translate to display of it.

\section{Conclusion}

In all of the questions above, a clear difference emerged in the responses given by Group $A$ comprising of the millennials and Group B comprising of parents, teachers or guardians. Millennials generally rated themselves higher on the scale of attitudes and mannerisms than did the parents, teachers or guardian group. The differences in the ratings for some of the questions exceeded $60 \%$ between the 2 groups of participants.

It can be concluded that the millennials rate themselves and those of their generation as more polite, with better attitudes and mannerism. However, the older generation disagrees with them. It is clear from the findings above that in general, the older generation does not find the millennials to be as polite or as having the attitudes and mannerisms they claim to possess. Some of the factors that contribute to this phenomenon as indicated by both groups of participants include lack of parental guidance when both parents are working, they are not taught good manners both at home and at school, they learn from being treated in a similar manner from peers, they are influenced by the social media and more importantly they lack good role models.

The empirical findings of this study clearly support previous studies that our young people today lack good manners towards each other as well as towards those older, fall short of feelings of empathy, compassion or kindness and inadequately meet the level of mannerisms expected of them by the older generation (Dass, Subramaniam, Muslia, \& Hasan, 2021). In summary, their moral values have changed (Wachege \& Rugendo, 2017) while their religious 
practices have corroded (Menhas et al., 2015). Some recommendations that could be put forward to tackle this issue include endeavours to instil good mannerisms from a young age by both parents and teachers which calls for a concerted effort by schools as well as religious institutions and an initiation of inter-generational programs by local education authorities to reduce inter-generational conflicts as well as to help the young obey, respect and value the older generation .

\section{Acknowledgement}

The authors would like to thank UITM for funding the study from the grant given by BESTARI PERDANA . Project title: Raising Ethical $Y$ and $Z$ Generations for a Civilised Malaysia. RMI Fail No: 600-IRMI/DANA 5/3/BESTARI (P) (026/2018)

\section{References}

Arumugam, N., Dass, L., Alias, M., Kaur, N., Abdul Murad, N., \& Nayan, S. (2015). Step-up academic writing styles. Kuala Lumpur, Malaysia: UiTM Press.

Awang, H., Dollah, A., Yusof, Y., Hanafi, N. M., \& Faiz, N. S. M. (2017). Personality and learning styles towards the pactical-based approach. International Journal of Information and Education Technology, Vol. 7(7), 539-542.

Brown, P., \& Levinson, S. (1987). Politeness: Universals in language usage. Cambridge: Cambridge University Press.

Chung, C. (2019). Stay healthy and save up for old age. The Star, p. 14.

Dass, L. C., Subramaniam, G., Muslia S., \& Hasan, H. (2021). Mannerisms of millennials - A cross generational perception. International Journal of Asian Social Science. Vol 11 (1). 46 - 55. DOI: 10.18488. URL: www.aessweb.com

Heffernan, M. (2012). Willful blindness: Why we ignore the obvious at our peril. Bloomsbury, USA: Bloomsbury Publishing.

Kadir, J. M. A., Naghavi, N., Subramaniam, G., \& Halim, N. A. A. (2020). Unemployment among graduates - Is there a mismatch? International Journal of Asian Social Science. Vol 10 (10). 583 - 592. DOI: 10.18488. URL: www.aessweb.com

Khan, M. A., \& Arif, I. (2009). Media imperialism and its effects on culture of Pakistan: A case study of youth of Multan. Global Media Journal; Pakistan Edition. pp.184.

Li, C. C., Luqman, A., \& Ishak, M. F. (2019). Modelling of civil servants' environment conservation behaviour using cognitive and non-cognitive factors. Malaysia Journal of Consumer and Family Economics, Vol. 23, 23-46.

Manning, T. (2013). Who are the millennials? Central Piedmont Community College. Retrieved May 24, 2013. Retrieved from https://www.cpcc.edu/millennial.

Meng, C. C. (2019). A Study on the effects of children's attitude toward elder by intergenerational programs. International Journal of Information and Education Technology, Vol. 9 (12), $898-903$.

Menhas, R., Umer, S., Akhtar, S., \& Shabbir, G. (2015). Impact of modernisation on religious institution: A case study of Khyber Pakhtun Khwa, Pakistan. European Review of Applied Sociology, 8(10), 23-28.

Mulyana, D., Soeaidy, M. S., \& Taufiq, A. R. (2019). Millennial urban generations: Does become "A Current Generation" shift their attention to financial literacy? Malaysia Journal of Consumer and Family Economics, Vol. 22, 19-27. 
Hee, O. C., \& Rhung, L. X. (2019). Motivation and employee retention among millennials in Malaysia. International Journal of Academic Research in Business \& Social Sciences, $9(2), 876-884$.

Pandian, A., Baboo, S. B., \& Yi, L. J. (2020). Reading the 21st century world: Self-assessment of digital media literacy among secondary school students in Malaysia. International Journal of Asian Social Science. Vol 10 (7). 350 - 359. DOI: 10.18488. URL: www.aessweb.com

Rozlan, N. Z. A., \& Subramaniam, G. (2020). The impact of flexible working arrangements on millennials - A conceptual analysis. International Journal of Academic Research in Business \& Social Sciences, 10(11), 938-948.

Sezan, T. (2012). Impact of western culture on young generation. http://sezanswritings.blogspot.com/2012/05/impact-of-western-culture-on young.html

Tamban V. E., \& Lazaro, M. P. (2018). Classroom etiquette, social behavior and the academic performance of college of teacher education students at the Laguna State Polytechnic University, Los Baños Campus, A.Y. 2015-2016. 4th International Research Conference on Higher Education, KnE Social Sciences (pp. 1198-1204). DOI 10.18502/kss.v3i6.2446

Twenge, J. M. (2014). Generation me: Why today's young Americans are more confident, assertive, entitled-and more miserable than ever before. New York, N.Y.: Atria Paper. Simon \& Schuster, Inc.

Wachege, P., \& Rugendo, F. (2017). Effects of modernisation on youths' morality: A case of Karuri Catholic Parish, Kenya. International Journal of Academic Research in Business and Social Sciences. 7(12), 691-711.

Yi-bo, Y. (2015). The comparative study on politeness between Chinese and English. US-China Foreign Language, Vol. 13 (7), pp. 544-549 doi:10.17265/1539-8080/2015.07.009 